\title{
V. Electrical measurement by alternating currents
}

\section{Henry A. Rowland}

To cite this article: Henry A. Rowland (1898) V. Electrical measurement by alternating currents, Philosophical Magazine Series 5, 45:272, 66-85, DOI: 10.1080/14786449808621105

To link to this article: http://dx.doi.org/10.1080/14786449808621105

曲 Published online: 08 May 2009.

Submit your article to this journal $\pi$

Џll Article views: 3

Q View related articles $₫$ 
V. Electrical Measurement by Alternating Currents. By HeNRy A. Rowland, Johns Hopkins University, Baltimore, $M d .^{*}$

\section{[Plate XIX.]}

THE electrical quantities pertaining to an electric current which it is nsually necessary to measure, in addition to current, electromotive force, watts, \&c., are resistances, self and mutnal inductances, and capacities. I propose to treat of the measurement of alternating currents, electromotive force, and watts in a separate paper. Resistances are ordinarily best dealt with by continuous currents, except liquid resistances. I propose to treat in this paper, however, mainly of inductances, self and mutual, and of capacities together with their ratios and values in absolute measure as obtained by alternating currents. I also give a few methods of resistance measurement more accurate than usually given by means of telephones or electrodynamometer as commonly used and specially suitable for resistances of electrolytic liquids.

I have introduced many new and some old methods depending upon making the whole current through a given branch circuit equal to zero. These always require two adjustments and they must often be made simultaneously. However, some of them admit of the adjustments being made independently of each other, and these, of course, are the most convenient. But none of these zero methods admit of any great accuracy unless very heavy currents are passed through the resistances. The reason of this is that an electrodynamometer cannot be made nearly as sensitive for small currents as a magnetic galvanometer. The deflexion of an electrodynamometer is as the square of the current. To make it doubly sensitive requires double the number of turns in both the coils. Hence we quickly reach a limit of sensitiveness. It is easy to measure an alternating current of $\cdot 0001$ ampere and difficult for 00001 ampere. A telephone is more sensitive and an instrument made by suspending a piece of soft iron at an angle of $45^{\circ}$, as invented by Lord Rayleigh, is also probably more sensitive.

For this reason I have introduced here many new methods depending upon adjusting two currents to a phase-difference of $90^{\circ}$, which I believe to be a new principle. This I do by passing one current through the fixed and the otber through the suspended coil of an electrodynamometer. By this means a heavy current can be passed through the fixed coils and a

* Communicated by the Author. 
minute current through the movable coil, thas multiplying the sensitiveness possibly 1000 times over the zero current method.

I have also found that many of the methods become very simple if we use mutual inductances made of wires twisted together and wound into coils. In this way the self-inductances of the coils are all practically equal and the mutual inductances of pairs of coils also equal. Hence we have only to measure the minute difference of these two to reduce the constants of the coil to one constant, and yet by proper connexions we can vary the inductances in many ratios. Three wires is a good number to use. However, the electrostatic induction between the wires must be carefully allowed for or corrected if much greater accuracy than $\overline{100}$ is desired.

By these various methods the measurement of capacities and inductances has been made as easy as the measurement of resistances, while the accuracy has been vastly improved and many sources of error suggested.

Relative results are more accurate than absolute as the period of an alternating current is difficult to determine, and its wave-form may depart from a true sine-curve.

Let self-inductances, mutual inductances, capacities, and resistances be designated by $\mathrm{L}$ or $l, \mathrm{M}$ or $m, \mathrm{C}$ or $c$, and $\mathrm{R}$ or $r$ with the same suffixes when they apply to the same circuit, the mutual inductance having two suffixes. Let $b$ be $2 \pi$ times the number of complete periods per second, or $b=2 \pi n$. The quantities $b \mathrm{~L}, b \mathrm{M}$ or $\frac{1}{\mathrm{C}}$ are of the dimensions of resistance and thus $\frac{\mathrm{L}}{\mathrm{M}}, b^{2} \mathrm{LC}$ or $b^{2} \mathrm{MC}$ have no dimensions. $b^{2} \mathrm{LM}$, $\frac{\mathrm{L}}{\mathrm{C}}$ or $\frac{\mathrm{M}}{\mathrm{C}}$ have dimensions of the square of resistances.

Where we have a mutual inductance $\mathrm{M}_{12}$, we have also the two self-inductances of the coils $\mathrm{I}_{1_{1}}$ and $\mathrm{L}_{2}$. When these coils are joined in the two possible manners, the self-inductance of the whole is

$$
\mathrm{L}_{1}+\mathrm{L}_{2}+2 \mathrm{M}_{12} \text { or } \mathrm{I}_{1}+\mathrm{L}_{2}-2 \mathrm{M}_{12} \text {. }
$$

In case of a twisted wire coil the last is very small. Likewise $\mathrm{L}_{1} \mathrm{~L}_{2}-\mathrm{M}_{12}^{2}$ will be very small for a twisted wire coil, as is found by multiplying the first two equations together.

If there are more coils we can write similar equations. For three coils we have

$$
\begin{array}{rr} 
& \mathrm{L}_{1}+\mathrm{L}_{2}+\mathrm{L}_{3}+2 \mathrm{M}_{12}+2 \mathrm{M}_{13}+2 \mathrm{M}_{23} \\
\text { 1. } & \mathrm{I}_{1}+\mathrm{L}_{2}+\mathrm{L}_{3}-2 \mathrm{M}_{12}-2 \mathrm{M}_{13}+2 \mathrm{M}_{23} \\
\text { 2. } & \mathrm{L}_{1}+\mathrm{L}_{2}+\mathrm{L}_{3}-2 \mathrm{M}_{12}+2 \mathrm{M}_{13}-2 \mathrm{M}_{23} \\
\text { 3. } & \mathrm{L}_{1}+\mathrm{L}_{2}+\mathrm{L}_{3}+2 \mathrm{M}_{12}-2 \mathrm{M}_{13}-2 \mathrm{M}_{23} \\
& \mathrm{~F} 2
\end{array}
$$


Connecting them in pairs, we have the self-inductances

$$
\begin{array}{lll}
\mathrm{I}_{1}+\mathrm{L}_{2}+2 \mathrm{M}_{12} & \mathrm{~L}_{1}+\mathrm{L}_{3}+2 \mathrm{M}_{13} & \mathrm{~L}_{2}+\mathrm{L}_{3}+2 \mathrm{M}_{23} \\
\mathrm{~L}_{1}+\mathrm{L}_{2}-2 \mathrm{M}_{12} & \mathrm{~L}_{1}+\mathrm{L}_{3}-2 \mathrm{M}_{13} & \mathrm{~L}_{2}+\mathrm{L}_{3}-2 \mathrm{M}_{23}
\end{array}
$$

There are many advantages in twisting the wires of the standard inductance together, but it certainly increases the electrostatic action between the coils. This latter source of error must be constantly in mind, however, and, for great accuracy, calculated and corrected for. But by proper choice of method we may sometimes eliminate it.

For the most accurate standards, I am rather doubtful about the use of twisted wire coils, at least without great caution. But for many purposes it certainly is a great convenience, especially where only an accuracy of one per cent. is desired. In some calculations I have made, I have obtained corrections of from one to one-tenth per cent. from this cause.

For twisted wires the above results reduce to $3 \mathrm{~L}+6 \mathrm{M}$, 3L-2M. Similar equations can be obtained for a larger number of wires. For twisted wire coils, $n$ wires joined abreast, the self-induction is $\frac{\mathrm{L}+(n-1) \mathrm{M}}{n}$, which is practically equal to $L$ or $M$. The resistance is $R / n$.

When we have $n=p+m$ wires twisted and wound in a coil and we connect them $p$ direct and $m$ reverse, the resistance and self-induction will be

$\frac{n \mathrm{R}^{3}+b^{2} \mathrm{R}[\mathrm{AC}+\mathrm{BC}-n \mathrm{AB}]}{(n \mathrm{R})^{2}+(b \mathrm{C})^{2}}$ and $\frac{\mathrm{R}^{2}[n(\mathrm{~A}+\mathrm{B})-\mathrm{C}]+b^{2} \mathrm{ABC}}{(n \mathrm{R})^{2}+(b \mathrm{C})^{2}}$

where $R$ is the resistance of one coil and

$$
\begin{aligned}
& \mathrm{A}=\mathrm{L}+(n-1) \mathrm{M} \\
& \mathrm{B}=\mathrm{L}-\mathrm{M} \\
& \mathrm{C}=n \mathrm{~L}+(4 m p-n) \mathrm{M} .
\end{aligned}
$$

This gives self-inductances and resistances equal to or less than $L$ and $R$. The correction for electrostatic induction remains to be put in. For the general case, the equation is very complicated for coils abreast, with mutual inductances.

The number of mutual inductances to be obtained is $M$ for two wires, $0, \mathrm{M}, 2 \mathrm{M}$ for three wires, $0, \mathrm{M}, 2 \mathrm{M}, 3 \mathrm{M}$ for four wires, \&c. From these results we see that we are always able to reduce mutual to self-inductance. Measuring the self-inductance of a coil connected in different ways, we can always determine the mutual inductances in terms of the self-inductances. 
Thus we need not search for methods of directly comparing mutual inductances with each other, although $I$ have given two of these, but we can content ourselves with measuring self-inductances and capacities. Fortunately most of the methods are specially adapted to the latter, the ratio of selfinductance to capacity being capable of being determined with great exactness by many methods.

In the use of condensers I have met with great difficulty from the presence of electric absorption. I have found that this can be represented by a resistance placed in the circuit of the condenser, which resistance is a function of current period.

I have developed Maxwell's theory of electric absorption in this manner. Correcting his equations for a small error, I have developed the resistance and capacity of a condenser as follows:

Let a condenser be made of strata of thicknesses $a_{1}, a_{2}$, \&c., and specific inductive capacities $k_{1}, k_{2}, \& c$, and resistances $p_{1}, p_{2}$, \&c. Then we have

$$
\begin{aligned}
& \mathrm{R}=\frac{\mathrm{B}_{0}}{b^{2}}-\frac{\mathrm{B}_{2}}{b^{4}}+\frac{\mathrm{B}_{4}}{b^{6}}-\& \mathrm{c}, \\
& \frac{1}{\mathrm{C}}=\mathrm{A}_{0}-\frac{\mathrm{A}_{2}}{b^{2}}+\frac{\mathrm{A}_{4}}{b^{4}}-\& \mathrm{c} .
\end{aligned}
$$

where

\&c.

$$
\begin{aligned}
& \mathrm{B}_{0}=\frac{a_{1}}{r_{1} k_{1}^{2}}+\frac{a_{2}}{r_{2} k_{2}^{2}}+\& c . \\
& \mathrm{B}_{2}=(4 \pi)^{2}\left\{\frac{a_{1}}{r_{1}^{3} k_{1}^{4}}+\frac{a_{2}}{r_{2}^{3} k_{2}^{4}}+\& c .\right\} \\
& \mathrm{B}_{4}=(4 \pi)^{4}\left\{\frac{a_{1}}{r_{1}^{5} k_{1}{ }^{6}}+\& c .\right\}
\end{aligned}
$$

$$
\begin{aligned}
& \mathrm{A}_{0}=4 \pi\left\{\frac{a_{1}}{k_{1}}+\frac{a_{2}}{k_{2}}+\& \mathrm{cc}\right\} \\
& \mathrm{A}_{2}=(4 \pi)^{3}\left\{\frac{a_{1}}{r_{1}^{2} k_{1}^{3}}+\frac{a_{2}}{r_{2}^{2} k_{2}^{3}}+\& c .\right\}
\end{aligned}
$$

\&c.

Mr. Penniman has experimented in the Johns Hopkins University laboratory with condensers by method 25 and found some interesting results. With a mica standard condenser of $\frac{1}{8}$ microfarad he was not able to detect any electric 
absorption, although I have no doubt one of the more accurate methods will show it.

With a condenser, probably of waxed paper, he found :-

$\begin{array}{ccc}\text { Number of complete } & \begin{array}{c}\text { Capacity in } \\ \text { microfarads. }\end{array} & \begin{array}{c}\text { Apparent resistance } \\ \text { in ohms. }\end{array} \\ \text { periods per second. } & 4 \cdot 64 & 139 \cdot 6 \\ 14 \cdot 0 & 4 \cdot 96 & 34 \cdot 1 \\ 32 \cdot 0 & 4 \cdot 96 & 20 \cdot 5 \\ 53 \cdot 3 & 4.94 & 5 \cdot 2\end{array}$

The first value of the capacity seems to be in error, possibly one of calculation. However, the result seems to show a nearly constant capacity but a resistance increasing rapidly with decrease of period, as Maxwell's formula shows. The constant value of the capacity remains to be explained.

Mr. Penniman will continue the investigation with other condensers, liquid and solid, as well as plates in electrolytic liquids.

The results in the other measurements have been fairly satisfactory, but many of the better methods have only been recently discovered and are thus untried. But we must acknowledge at once that work of the nature here described is most liable to error. Every alternating current has, not only its fundamental period, but also its harmonics, so that very accurate absolute values are almost impossible to obtain without great care. To eliminate them, I propose to use an arrangement of two parallel circuits, one containing a condenser and the other a self-inductance, each with very little resistance. The long-period waves will pass through the second side and the short ones through the condenserside. By shunting off some of the current from the second side, it will be more free from harmonics than the first one.

However, in a multipolar dynamo, especially one containing iron, there is danger of long-period waves also, which this method might intensify. A second arrangement, using the condenser side, might eliminate them. However, many dynamos without iron and without too many poles and properly wound produce a very good curve without harmonies, especially if the resistance in the circuit is replaced by a selfinductance having no iron. These remarks apply only to absolute determinations. Ratios of inductance, self and mutual, and capacity are independent of the period, and thus it can always be eliminated. Measurements of resistances also are independent.

But there are other errors which one who has worked with continuous currents may fall into. Nearly all alternating 
currents generate electromagnetic waves which are so strong that currents exist in every closed circuit with any opening: between conductors in the vicinity.

We eliminate this source of error by twisting wires together and other expedients. But in avoiding one error, we plunge into another. For, by twisting wires we introduce electrostatic capacity between them, which may vitiate our results. Thus, in methods 23 or 24 for comparing mutual inductances, if there is electrostatic capacity between the wires, a current will flow through the electrodynamometer in the testing: circuit and destroy the balance.

Various expedients suggest themselves to eliminate this trouble, as, for instance, the variation of the resistance $A$ in the above; but I shall reserve them for a future paper. I may say, however, that it is sometimes possible, as in method 12 for instance, to choose a method in which the orror does not exist.

However, with the very best method, much rests with the experimenter, as errors from electromagnetic and electrostatic induction are added to errors from defective insulation when we use alternating currents.

These errors are generally less than one per cent., however, and intelligent and careful work reduces them to less than this.

The following methods generally refer by number to Plate XIX., on which the resistances \&c. are generally marked. One large circle with a small one inside represents an electrodynamometer. Of course the circuit of the small coil can be interchanged with the large one. Generally we make the smaller current go through the banging coil.

By the methods 1 to 14 , we adjust the electrodynamometer to zero by making the phase-difference in the two coils $90^{\circ}$. For greatest sensitiveness, the currents through the two coils must be the greatest possible, heating being the limit. This current should be first calculated from the impedance of the circuit, as there is danger of making it too great.

In the second series of methods, 15-26, the branch circuit in which the current is to be 0 is indicated by 0 .

Resistances in the separate cireuits are represented by $R R^{\prime}$ $\mathrm{R}$, \&c., and $r r^{\prime} r$, \&c. Corresponding self-inductances and capacities in the same circuits are $\mathrm{L} \mathrm{L}^{\prime} \mathrm{L}, \& c$. , and $l l^{\prime} l$, \&c., or $\mathrm{C}^{\prime} \mathrm{C}$, \&c., and $c c^{\prime} c$, \&c. $b=2 \pi n$, where $n$ is the number of complete current waves per second.

The currents must be as heavy as possible, $\frac{1}{10}$ ampere or more, and it is well to make those that require a current of more than $\frac{1}{100}$ ampere of larger wire freely suspended in oil. A larger current can, however, be passed through an ordinary 
Phil. Mag. S. 5. Vol. 45. PI. XIX.
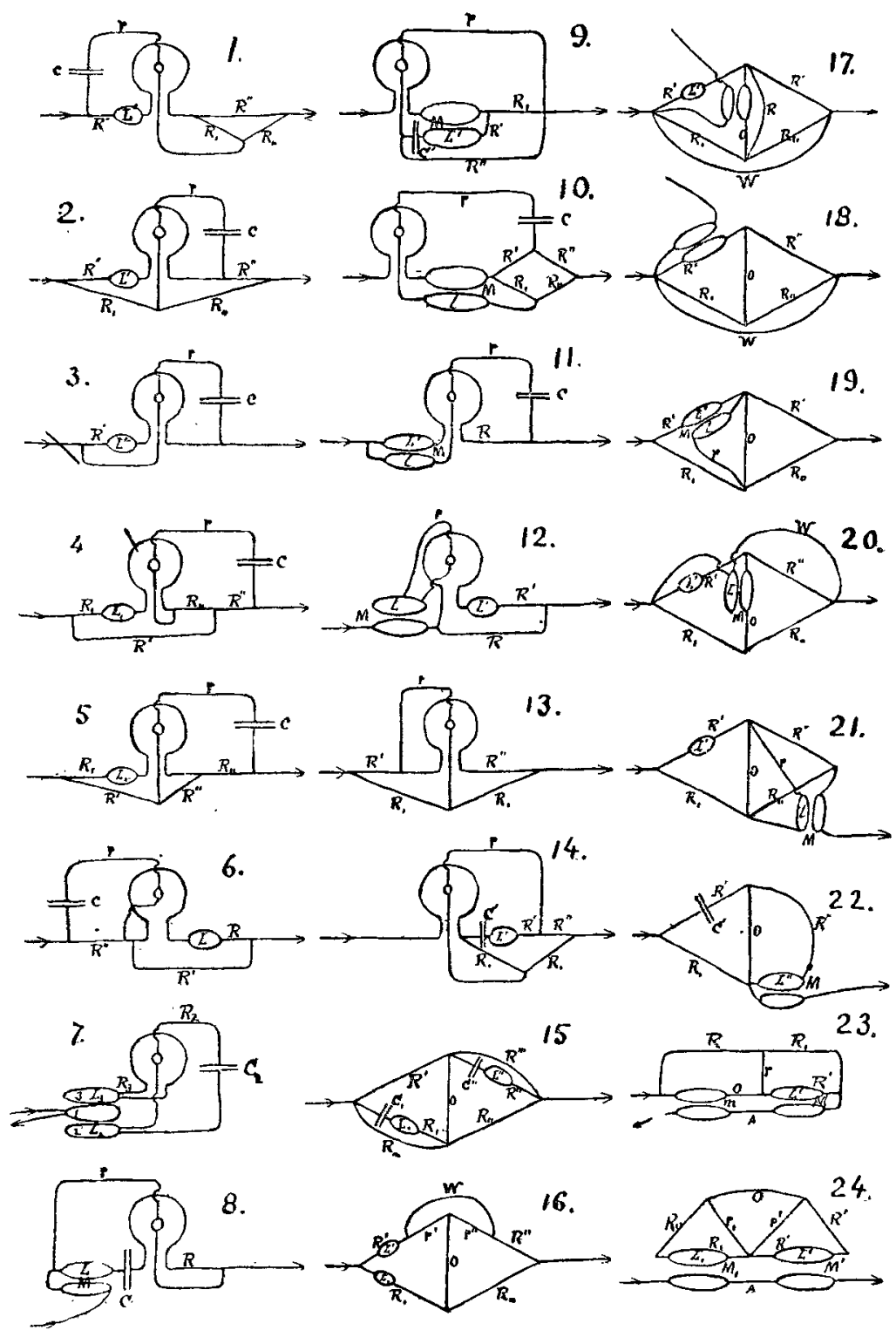
resistance-box for a second or two without danger. A few fixed coarse resistances of large wire in air or oil with ordinary resistance-boxes for fine adjustment, are generally all that are required. Special boxes avoiding electrostatic induction are, however, the best, but are not now generally obtainable.

In some methods, such as $8,9,10$, \&c., we can eliminate undesirable terms containing the current period by using a key which suddenly changes the connexions before the period has time to change much.

In using twisted-wire mutual inductances, methods 7 and 12 are about or entirely free from error dne to electrostatic action between the wires. In all the methods this error is less when the resistance of the coils is least, and in 23 and 24 when $\mathrm{A}$ is least. In method 8 the error is very small when the coilresistances and $\mathrm{R}$ are small and $r$ great. In this method with 1 henry and 1 microfarad, the error need not exceed 1 in 1000. Probably the same remarks apply to 9, 10, 11 also. By suitable adjustment of resistances in the other method, the error may be reduced to a minimum. It can, of course, be calculated and corrected for.

An electrodynamometer can be made to detect 0001 ampere without making the self-induclance of the suspended coil more than $\cdot 0007$ henry or that of the stationary coils more than $\cdot 0006$ henry, the latter coil readily sustaining a current of $\frac{1}{10}$ ampere without much heating.

An error may creep in by methods $1-14$ if the current through the suspension is too great, thus heating it and possibly twisting it. This should be tested by short-circuiting the suspended coil or varying the current. This error can be eliminated by always observing by reversing the current in one coil.

Inductances containing iron introduce harmonics and vary with current strength. Thus they have no fixed value.

Closed circuits or masses of metal near a self-inductance diminish it, and increase the apparent resistance, which effects vary with the period. Short circuits in coils are thus detected.

Electrolytic cells act as capacities which, as well as the apparent resistance, vary with the current period. They also introduce harmonics. The same may be said of an electric arc.

An incandescent lamp or hot wire introduces harmonies into the circuit.

Hysteresis in an iron inductance acts as an apparent resistance in the wire almost independent of the current period, and does not, of itself, introduce harmonics. The harmonics are due to the variation of the magnetic permeability with the amount of magnetization. 
Electric absorption in a condenser acts as a resistance varying with the square of the period, the capacity also varying, as I have shown above.

In general any circuit containing resistances, inductances, and capacities combined acts as a resistance and inductance or capacity, both of which vary with the current period, the square of the current period alone entering. For symmetry the square of the current period can alone enter in all these cases and those above.

Hence only inductances containing no iron or not near any closed metallic circuits have a fixed value. The same may be said of condensers, as they must be free from electric absorption or electrolytic action to have constants independent of the period. There is no apparent hysteresis in condensers and the constants do not apparently vary with the electrostatic force.

In Plate XIX. I have drawn the diagrams for the various methods, which are nearly self-explanatory. In methods 1 to 14 inclusive, the concentric circles are the coils of the electrodynamometer. Either one is the fixed coil and the other the hanging coil. Oblong figures are inductances, and when near each other are mutual inductances. A pair of cross-lines is a condenser. When a condenser and inductance are on the same circuit, we may, in general, leave out one or the other.

The following numbers indicate both the number of the method and the figures in Plate XIX.

Method 1.

$$
\frac{\mathrm{L}^{\prime}}{c}=\frac{\left[r\left(\mathrm{R}_{,}+\mathrm{R}^{\prime \prime}\right)+\mathrm{R}_{\prime \prime}\left(r+\mathrm{R}_{\ell}\right)\right]\left[\mathrm{R}^{\prime}\left(\mathrm{R}_{,}+\mathrm{R}_{\mu}\right)+\mathrm{R}^{\prime \prime}\left(\mathrm{R}_{\iota}+\mathrm{R}^{\prime}\right)\right]}{\left(\mathrm{R}_{/}+\mathrm{R}^{\prime \prime}+\mathrm{R}_{/ \prime}\right)^{2}} .
$$

Method 2.

$$
\begin{aligned}
& \frac{\mathrm{L}^{\prime}}{c} \text { or } b^{2} \mathrm{LL}^{\prime} \text { or }-\frac{1}{b^{2} c c^{\prime}}= \\
& \frac{\left[\mathrm{R}_{u \prime} \mathrm{R}^{\prime}-\mathrm{R}_{\imath} \mathrm{R}^{\prime \prime}\right]\left[\mathrm{R}_{t}\left(r+\mathrm{R}^{\prime \prime}\right)+\mathrm{R}_{u}\left(r+\mathrm{R}_{\imath}\right)\right]}{\mathrm{R}_{s i}\left(\mathrm{R}_{t}+\mathrm{R}_{u}\right)}
\end{aligned}
$$

\section{Method 3.}

In (1) make $\mathrm{R}^{\prime}=\mathrm{R}^{\prime \prime}=\mathrm{R}_{l l}=0$, or in (2) make $\mathrm{R}^{\prime \prime}=\mathrm{R}_{l}=0$,

$$
\mathrm{R}_{\| \prime}=\infty \text {. Hence } \frac{\mathrm{L}^{\prime}}{c}=r \mathrm{R}^{\prime} \text {. }
$$

In case the circuit $r$ contains some self-inductance, $l$, we can correct, for it by the equation

$$
\frac{\mathrm{L}^{\prime}}{c}=r \mathrm{R}^{\prime}\left(1-\frac{1}{b^{2} l_{c}}\right)
$$


Method 4.

$$
\frac{\mathrm{L}_{1}}{c}=\frac{\left[\mathrm{R}^{\prime}\left(r+\mathrm{R}_{\mu \prime}\right)+\mathrm{R}^{\prime \prime}\left(\mathrm{R}^{\prime}+\mathrm{R}_{\prime \prime}\right)\right]\left[\mathrm{R}^{\prime}\left(\mathrm{R}^{\prime \prime}+\mathbf{R}_{u \prime}\right)+\mathrm{R}^{\prime \prime}\left(\mathrm{R}_{1}+\mathrm{R}_{\mu \prime}\right)\right]}{\mathrm{R}^{\prime} \mathrm{R}^{\prime \prime}} .
$$

Method 5.

$$
\frac{\mathrm{L}_{1}}{c}=\frac{\left[\mathrm{R}_{l}\left(\mathrm{R}^{\prime \prime}+\mathrm{R}_{\mu \prime}\right)+\mathrm{R}_{\mu l}\left(\mathrm{R}^{\prime}+\mathrm{R}^{\prime \prime}\right)\right]\left[\mathrm{R}^{\prime}\left(\mathrm{R}^{\prime \prime}+\mathrm{R}_{\mu}\right)+r\left(\mathrm{R}^{\prime}+\mathrm{R}^{\prime \prime}\right)\right]}{\left(\mathrm{R}^{\prime}+\mathrm{R}^{\prime \prime}\right)\left(\mathrm{R}^{\prime \prime}+\mathrm{R}_{\|}\right)} .
$$

Method 6.

$$
\frac{\mathrm{L}}{c} \text { or } \frac{l}{\mathrm{C}}=\left(\mathrm{R}+\mathrm{R}^{\prime}\right)\left(\mathrm{R}^{\prime \prime}+r\right) \text {. }
$$

We can correct for self-inductions $L^{\prime}, L^{\prime \prime}$ in the circuits $R^{\prime}, R^{\prime \prime}$ by using the exact equation

$$
\begin{gathered}
b^{2}\left[\left[\mathrm{~L}^{\prime}\left(r+\mathrm{R}^{\prime \prime}\right)+\left(\mathrm{L}^{\prime \prime}-\frac{1}{b^{2}}\right) \mathrm{R}^{\prime}\right]\left[\mathrm{L}^{\prime \prime}\left(\mathrm{R}+\mathrm{R}^{\prime}\right)+\mathrm{R}^{\prime \prime}\left(\mathrm{L}+\mathrm{L}^{\prime}\right)\right]+\right. \\
\mathrm{R}^{\prime} \mathrm{R}^{\prime \prime}\left(r^{\prime}+\mathrm{R}^{\prime \prime}\right)\left(\mathrm{R}+\mathrm{R}^{\prime}\right),
\end{gathered}
$$

or approximately

$$
\begin{aligned}
\frac{\mathrm{L}}{c}=\left(\mathrm{R}+\mathrm{R}^{\prime}\right)\left(\mathrm{R}^{\prime \prime}+r\right) & -\frac{\mathrm{L}^{\prime}}{c}-\frac{\mathrm{L}^{\prime \prime}}{c} \frac{\mathrm{R}+\mathrm{R}^{\prime}}{\mathrm{R}^{\prime \prime}}+b^{2} \frac{\mathrm{L}\left[\mathrm{L}^{\prime}\left(r+\mathrm{R}^{\prime \prime}\right)+\mathrm{L}^{\prime \prime} \mathrm{R}^{\prime}\right]}{\mathrm{R}^{\prime}} \\
& +\& c .
\end{aligned}
$$

\section{Method 7.}

$$
\mathrm{R}_{2} \mathrm{R}_{3} \mathrm{M}_{12} \mathrm{M}_{13}+b^{2}\left[\mathrm{~L}_{3} \mathrm{M}_{12}-\mathrm{M}_{23} \mathrm{M}_{13}\right]\left[\mathrm{L}_{2} \mathrm{M}_{13}-\mathrm{M}_{33} \mathrm{M}_{12}\right]=0 \text {. }
$$

For a coil containing three twisted wires, $M_{32}=M_{13}=M_{23}$ and the self-inductions of the coils are also equal to each other and nearly equal to the mutual inductions. Put an extra selfinduction $L_{3}$ in $R_{3}$ and a capacity $C_{2}$ in $R_{2}$. Replace $L_{3}$ by $\mathrm{L}_{1}+\mathrm{I}_{3}$ and $\mathrm{L}_{2}$ by $\mathrm{L}-\frac{1}{b^{2} \mathrm{C}_{2}}$ and we can write

$$
\frac{\mathrm{L}_{3}+\mathrm{L}-\mathrm{M}}{\mathrm{C}_{2}}=\mathrm{R}_{2} \mathrm{R}_{3}+b^{2}(\mathrm{~L}-\mathrm{M})\left(\mathrm{L}_{3}+\mathrm{L}-\mathrm{M}\right) .
$$

As $\mathrm{L}-\mathrm{M}$ is very small and can be readily known, the formula will give $\frac{\mathrm{L}_{3}}{\mathrm{C}_{2}}$. When $\mathrm{L}-\mathrm{M}=0$ we have

$$
\frac{\mathrm{L}_{2}}{\mathrm{C}_{3}} \text { or } \frac{\mathrm{L}_{3}}{\mathrm{C}_{2}}=\mathrm{R}_{2} \mathrm{R}_{3} \text {. }
$$


or

$$
b^{2} \mathrm{M}(\mathrm{M}+\mathrm{L})=r \mathrm{R} \quad 2 b^{2} \mathrm{M}^{2}=r \mathrm{R}+(r \mathrm{R})^{\prime}
$$

\section{Method 8.}

$$
b^{2} \mathrm{M}(\mathrm{M}-\mathrm{L})=(r \mathrm{R})^{\prime} \quad 2 b^{2} \mathrm{LM}=r \mathrm{R}-(r \mathrm{R})^{\prime} .
$$

Placing a capacity in the circuit $R$, we have also

$$
b^{2} \mathrm{M}(\mathrm{M}+\mathrm{L})-\frac{\mathrm{M}}{\overline{\mathrm{C}}}=r \mathrm{R},
$$

or

$$
b^{2} \mathrm{M}(\mathrm{M}-\mathrm{L})+\frac{\mathrm{M}}{\mathrm{C}}=r \mathrm{R} .
$$

To correct for the self-induction, $l$, of $r$ we have the exact equations

$$
\begin{aligned}
& b^{2} \mathrm{M}(\mathrm{M}+\mathrm{L})=r \mathrm{R}+b^{2} l(\mathrm{~L}+\mathrm{M}) \\
& b^{2} \mathrm{M}(\mathrm{M}-\mathrm{L})=r \mathrm{R}+b^{2} l(\mathrm{~L}-\mathrm{M}) \\
& b^{2} \mathrm{M}(\mathrm{M}+\mathrm{L})-\frac{\mathrm{M}}{\mathrm{C}}=r \mathrm{R}-b^{2} l\left(\mathrm{~L}+\mathrm{M}-\frac{1}{b^{2} \mathrm{U}}\right) \\
& b^{2} \mathrm{M}(\mathrm{M}-\mathrm{L})+\frac{\mathrm{M}}{\mathrm{C}}=r \mathrm{R}-b^{2} l\left(\mathrm{~L}-\mathrm{M}-\frac{1}{b^{2} \mathrm{C}}\right)
\end{aligned}
$$

If the condenser is put in $r$, we have

$$
\frac{\mathrm{L}+\mathrm{M}}{c}=r \mathrm{R}-b^{2} \mathrm{M}(\mathrm{L}+\mathrm{M})
$$

or

$$
\begin{gathered}
\frac{\mathrm{L}-\mathrm{M}}{e}=r \mathrm{R}+b^{2} \mathrm{M}(\mathrm{L}-\mathrm{M}) . \\
\text { Method } 9 . \\
b^{2} \mathrm{~L}^{\prime} \mathrm{M}-\frac{\mathrm{M}}{\mathrm{C}^{\prime}}=\mathrm{R}_{i}\left[\mathrm{R}^{\prime}+\mathrm{R},+\frac{r \mathrm{R}^{\prime \prime}}{r+\overline{\mathrm{R}}^{\prime \prime}}\right]
\end{gathered}
$$

or

$$
-b^{2} \mathrm{~L}^{\prime} \mathrm{M}+\frac{\mathrm{M}}{\mathrm{C}^{\prime}}=\mathrm{R}_{\iota}\left[\mathrm{R}^{\prime}+\mathrm{R},+\frac{r \mathrm{R}^{\prime \prime}}{r+\overline{\mathrm{R}}^{\prime \prime}}\right] .
$$

Making $\mathrm{R}^{\prime \prime}=\infty$ and $r+\mathrm{R}^{\prime}=r$, we have

$$
-b^{2} \mathrm{~L}^{\prime} \mathrm{M}+\frac{\mathrm{M}}{\bar{c}^{\prime}} \quad \text { or } \quad b^{2} \mathrm{~L}^{\prime} \mathrm{M}-\frac{\mathrm{M}}{\overline{\mathrm{C}^{\prime}}}=\mathrm{R}_{/}\left(r+\mathrm{R}_{\jmath}\right) .
$$



have

Taking two observations we can eliminate $b^{2} \mathrm{~L}^{\prime} \mathrm{M}$, and we

$$
\frac{\mathrm{M}}{\mathrm{C}^{\prime}}=\mathrm{R},\left\{r-(r)^{\prime}\right\} \text {. }
$$

Knowing $\mathrm{L}^{\prime} \mathrm{M}$ we can find $\mathrm{C}^{\prime}$. Throwing out $\mathrm{C}^{\prime}$ (i. e. making it $\infty$ ) we can find $l^{2} L^{\prime} M$ in absolute measure : then put in $\mathrm{C}^{\prime}$ and find its value as above.

To correct for self-induction in $\mathbf{R}_{l}$, we have for case $\mathrm{R}^{\prime \prime}=\infty$ the exact equation

$$
b^{2} \mathrm{~L}^{\prime} \mathrm{M}-\frac{\mathrm{M}}{\mathrm{C}^{\prime}}=\mathrm{R}_{s}(r+\mathrm{R})+b^{2}\left[\mathrm{~L}^{\prime}+\mathrm{I}_{s}-\mathrm{M}\right] \mathrm{L}_{\jmath}-\frac{\mathrm{L}_{1}}{\mathrm{C}^{\prime}} .
$$

The correction, therefore, nearly vanishes for two twisted wires in a coil where $\mathrm{L}^{\prime}-\mathrm{M}=0$ and $\mathrm{C}$ is taken out.

\section{Method 10.}

$-b^{2} l \mathrm{M}+\frac{\mathrm{M}}{c}$ or $\quad b^{2} l \mathrm{M}-\frac{\mathrm{M}}{\mathrm{c}}=$

$\frac{\left[\mathrm{R}, \mathrm{R}^{\prime \prime}-\mathrm{R}_{\prime \prime} \mathrm{R}^{\prime}\right]\left\{r\left[\mathrm{R}^{\prime}+\mathrm{R}^{\prime \prime}+\mathrm{R}_{1}+\mathrm{R}_{\prime \prime}\right]+\left(\mathrm{R}^{\prime}+\mathrm{R}_{)}\right)\left(\mathrm{R}^{\prime \prime}+\mathrm{R}_{\prime \prime}\right)\right\}}{\left[\mathrm{R}^{\prime}+\mathrm{R}^{\prime \prime}+\mathrm{R}_{l}+\mathrm{R}_{u}\right]^{2}}$

This can be used in the same manner as 9 , to which it readily reduces. But it is more general and always gives zero deflexion when adjusted, however $M$ is connected. 'To throw out $\mathrm{C}$ makes it $\infty$.

\section{Method 11.}

$$
\begin{aligned}
& \frac{\mathrm{L}-\mathrm{M}}{c}=r \mathrm{R}+b^{2}(l-\mathrm{M})(\mathrm{L}-\mathrm{M}), \\
& \frac{\mathrm{L}+\mathrm{M}}{c}=r \mathrm{R}+b^{2}(l+\mathrm{M})(\mathrm{L}+\mathrm{M}) .
\end{aligned}
$$

For the upper equation the last term may be made small and the method may be useful for determining $L-M$ when $c$ is known. Method 8, however, is better for this.

Method 12.

$$
\frac{\mathrm{L}^{\prime}}{l}=\frac{\mathrm{R}+\mathrm{R}^{\prime}}{r} \text {. }
$$


Should the circuits $\mathrm{R}$ and $r$ also have small self-inductances, $\mathrm{L}$ and $l$, we can use the exact equation

$\mathrm{L}^{\prime}+\mathrm{L}=\frac{\mathrm{R}+\mathrm{R}^{\prime}}{r} l \frac{1+\frac{\mathrm{L} r}{l \mathrm{R}}}{1-\frac{b^{2} \mathrm{~L} l}{r \mathrm{R}}}=\frac{\mathrm{R}+\mathrm{R}^{\prime}}{r} l\left[1+\frac{\mathrm{L} r}{l \mathrm{R}}+\frac{b^{2} \mathrm{~L} l}{r \mathrm{R}}+\& \mathrm{c}.\right]$

When $L^{l}$ and $l$ are approximately known, we can write the following, using the approximate value on the right side of the equation,

$$
\frac{\mathrm{L}^{\prime}}{l}=\frac{\mathrm{R}+\mathrm{R}^{\prime}}{r^{\prime}}\left[1+\frac{\mathrm{L} r}{l \overline{\mathrm{R}}}-\frac{\mathrm{L}^{\prime}}{l} \frac{r}{\mathrm{R}+\mathrm{R}^{\prime}}+\frac{b^{2} \mathrm{~L} l}{r \mathrm{~L}}+\& c .\right]
$$

Taking out $\mathrm{L}^{\prime}$ and putting a condenser, $\mathrm{C}$, in $\mathrm{R}$ we have

$$
\frac{l}{\mathrm{C}}=r \mathrm{R}^{\prime}-b^{2} l \mathrm{CR}\left(\mathrm{R}+\mathrm{R}^{\prime}\right) \text {. }
$$

For a condenser, $\mathbf{R}$ can be small or zero.

\section{Method 13.}

(A) $\left[b \mathrm{~L}^{\prime \prime}-\frac{1}{b \mathrm{C}^{\prime \prime}}\right]^{2}=\frac{\left[\mathrm{R}_{l} \mathrm{R}^{\prime}-\mathrm{R}_{l} \mathrm{R}^{\prime \prime}\right]\left[\mathrm{R}_{l}\left(r+\mathrm{R}_{l}\right)+\mathrm{R}_{l}\left(r+\mathrm{R}^{\prime \prime}\right)\right]}{\mathrm{R}_{l}^{2}}$.

This determines capacities or self-inductions in absolute value. As described above, mutual induction can also be determined by converting it into self-induction.

(B) $\left[b \mathrm{~L}_{\| l}-\frac{1}{b \mathrm{C}_{l l}}\right]^{2}=\frac{\left[\mathrm{R}^{\prime \prime} \mathrm{R}_{l}-\mathrm{R}^{\prime} \mathrm{R}_{u}\right]\left[\mathrm{R}_{u l}\left(r+\mathrm{R}_{l}\right)+\mathrm{R}_{l}\left(r+\mathrm{R}^{\prime \prime}\right)\right]}{\mathrm{R}^{\prime}\left(r+\mathrm{R}_{l}\right)}$.
(C) $\left[b \mathrm{~L}_{l}-\frac{1}{b \mathrm{C}_{l}}\right]^{2}=\frac{\left[\mathrm{R}^{\prime} \mathrm{R}_{u}-\mathrm{R}^{\prime \prime} \mathrm{R}_{l}\right]\left[\mathrm{R}_{l}\left(r+\mathrm{R}^{\prime \prime}\right)+\mathrm{R}_{u l}\left(r+\mathrm{R}_{l}\right)\right]}{\mathrm{R}^{\prime \prime}\left[r+\mathrm{R}^{\prime \prime}+\mathrm{R}_{l l}\right]}$

$\left[b \mathrm{~L}^{\prime}-\frac{1}{b \mathrm{C}^{\prime \prime}}\right]^{2}=$

Method 14.

$$
\frac{\left[\mathrm{R}_{t} \mathrm{R}^{\prime \prime}-\mathrm{R}_{u} \mathrm{R}^{\prime}\right]\left\{r\left[\mathrm{R}^{\prime}+\mathrm{R}_{l}+\mathrm{R}^{\prime \prime}+\mathrm{R}_{u i}\right]+\left[\mathrm{R}^{\prime}+\mathrm{R}_{i}\right]\left[\mathrm{R}^{\prime \prime}+\mathrm{R}_{\mu}\right]\right\}}{\mathrm{R}_{\| /}\left[r+\mathrm{R}^{\prime \prime}+\mathrm{R}_{\| \prime}\right]} .
$$

Of course, in any of these equations, methods 13 or $14, L^{\prime \prime}$ is eliminated by making $L^{\prime \prime}=0$ or the condenser $U$ is omitted by making $\mathrm{C}=\infty$. 


\section{Method 15.}

$$
\begin{aligned}
& -\frac{1}{b^{2} \mathrm{C}_{1} \mathrm{C}^{\prime \prime}} \text { or } b^{2} \mathrm{~L}_{1} \mathrm{~L}^{\prime \prime} \text { or }-\frac{\mathrm{L}_{1}}{\mathrm{C}^{\prime}}= \\
& \frac{\mathbf{R}^{\prime} \mathbf{R}_{u}\left(\mathbf{R}_{t}+\mathbf{R}_{u l l}\right)\left(\mathbf{R}^{\prime \prime}+\mathbf{R}^{\prime \prime \prime}\right)-\mathbf{R}^{\prime \prime} \mathbf{R}_{t} \mathbf{R}^{\prime \prime \prime} \mathbf{R}_{u l \prime}}{\mathbf{R}^{\prime} \mathbf{R}_{u l}-\mathbf{R}^{\prime \prime \prime} \mathbf{R}_{u l}} .
\end{aligned}
$$

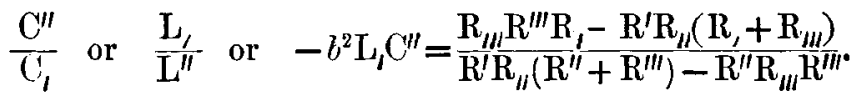

(A) When $R_{m}=\infty$ we have

$$
\begin{gathered}
\frac{\mathrm{L}_{l}}{\mathrm{U}^{\prime \prime}}=\frac{\mathrm{R}^{\prime} \mathrm{R}_{\mu}\left(\mathrm{R}^{\prime \prime}+\mathrm{R}^{\prime \prime \prime}\right)-\mathrm{R}^{\prime \prime} \mathrm{R}_{1} \mathrm{R}^{\prime \prime \prime}}{\mathrm{R}^{\prime \prime \prime}}=\mathrm{R}^{\prime} \mathrm{R}_{\mu}-\frac{\mathrm{R}^{\prime \prime}}{\mathrm{R}^{\prime \prime \prime}}\left[\mathrm{R}^{\prime \prime \prime} \mathrm{R}_{l}-\mathrm{R}^{\prime} \mathrm{R}_{\| l}\right] ; \\
\ell^{2} \mathrm{~L}_{,} \mathrm{C}^{\prime \prime}=\frac{\mathrm{R}^{\prime \prime \prime} \mathrm{R}_{\iota}-\mathrm{R}^{\prime} \mathrm{R}_{u}}{\mathrm{R}^{\prime \prime} \mathrm{R}^{\prime \prime \prime}} .
\end{gathered}
$$

If we adjust by continuous current, we shall have

$$
\mathrm{R}^{\prime \prime \prime} \mathrm{R}_{\iota}-\mathrm{R}^{\prime} \mathrm{R}_{\mu}=0 \text {. }
$$

For a condenser we can make $\mathrm{R}^{\prime \prime}=0$ provided there is no electric absorption. In this case $b^{2} \mathrm{~L}_{1} \mathrm{C}^{\prime \prime}$ is indeterminate and we can adjust to find $\frac{\mathrm{L}_{i}}{\mathrm{C}^{\prime \prime}}$. However, two simultaneous adjustments are required.

But I have shown that the presence of electric absorption in a condenser causes the same effect as a resistance in its circuit, the resistance, however, varying with the period of the current. Hence $\mathrm{R}^{\prime \prime}$ mist include this resistance. However, the value of $R^{\prime \prime}$ will not affect the first adjustment much and so the method is easy to work. If it is sensitive enough it will be useful in measuring the electric absorption of condensers in terms of resistance.

It has the advantage of being practically independent of the current period for $\frac{\mathrm{L}}{\mathrm{C}}$, as it should be.

For comparison of capacities the same simplification does not occur.

Indeed, the method is of very little value in this case, being surpassed by 16 .

Method 16.

(A) $\left[\mathrm{R}, \mathrm{R}^{\prime \prime}-\mathrm{R}_{\prime \prime}, \mathrm{R}^{\prime}\right]\left[\mathrm{W}+r^{\prime}+r^{\prime \prime}\right]+\mathrm{W}\left[\mathrm{R}, r^{\prime \prime}-r^{\prime} \mathrm{R}_{u}\right]=0$;

$$
\frac{\mathrm{L}}{\mathrm{L}_{l}} \quad \text { or } \quad \frac{\mathrm{C}_{l}}{\mathrm{C}^{\prime}}=\frac{\mathrm{R}^{\prime \prime}}{\mathrm{R}_{u}}+\frac{\left(\mathrm{W} r^{\prime \prime}\right)}{\mathrm{R}_{d \prime}\left(\mathrm{W}+r^{\prime}+r^{\prime \prime}\right)} \text {. }
$$


The first equation is satisfied by adjusting the Whentstone bridge so as to make

$$
\begin{gathered}
\left(\mathrm{R}_{\imath} \mathrm{R}^{\prime \prime}-\mathrm{R}_{w} \mathrm{R}^{\prime}\right)=0 ; \quad \mathrm{R}, r^{\prime \prime}-\mathrm{R}_{u} r^{\prime}=0 ; \\
\mathrm{R}_{\imath}\left(\mathrm{R}_{u}+r^{\prime \prime}\right)-\mathrm{R}_{u}\left(\mathrm{R}^{\prime}+r^{\prime}\right)=0 .
\end{gathered}
$$

That is

$$
\frac{\mathrm{R}_{l}}{\mathrm{R}_{/ /}}=\frac{\mathrm{R}^{\prime}}{\mathrm{R}^{\prime \prime}}=\frac{r^{\prime}}{r^{\prime \prime}}
$$

We can then adjust $\mathrm{W}$ with alternating currents. This is a very good method and easy of application, but requires many resistances of known ratio. Many of these, however, may be equal without disadvantage. A well-known case is given by making $r^{\prime}$ and $r^{\prime \prime}=0$.

(B) By placing self-inductions or condensers in $\mathrm{R}$, and $r^{\prime \prime}$ instead of the above we have the following

$$
\begin{aligned}
& \frac{c^{\prime \prime}}{{\overline{\mathrm{C}^{\prime}}}^{\prime}} \text { or }-b^{2} \mathrm{~L}_{,} c^{\prime \prime \prime} \text { or } \frac{\mathrm{L}_{1}^{\prime}}{l^{\prime \prime}}=\frac{\mathrm{R}_{,}\left(\mathrm{W}+\mathrm{R}^{\prime \prime}\right)-\mathrm{R}^{\prime} \mathrm{R}_{/ \prime}}{\mathrm{R}^{\prime \prime}\left(\mathrm{W}+r^{\prime}+r^{\prime \prime}\right) W^{\prime \prime}} \\
& -\frac{1}{b^{2} \mathrm{C}, c^{\prime \prime}} \text { or } \frac{\mathrm{L} /}{c^{\prime \prime}} \text { or }-l^{2} \mathrm{~L}, l^{\prime \prime}=
\end{aligned}
$$

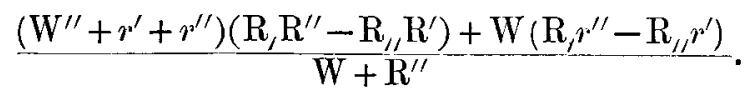

Making $\mathrm{R}^{\prime \prime}=0$, we have

$$
\begin{aligned}
& \frac{c^{\prime \prime}}{\mathrm{C}_{\prime}} \text { or }-b^{2} \mathrm{~L}_{\iota} e^{\prime \prime} \text { or } \mathrm{L}_{l^{\prime \prime}}=\frac{\mathrm{R}, \mathrm{W}-\mathrm{R}^{\prime} \mathrm{R}_{\prime \prime}}{\mathrm{W}_{\gamma^{\prime \prime}}} \\
& -\frac{1}{b^{2} \mathrm{C}_{\jmath} c^{\prime \prime}} \text { or } \frac{\mathrm{L}}{c^{\prime \prime}} \text { or }-b^{2} \mathrm{~L}_{\jmath} l^{\prime \prime}=\mathrm{R}^{\prime} \mathrm{R}_{/ /}+r^{\prime} \mathrm{R}_{/ /}\left(1+\frac{\mathrm{R}^{\prime}}{\mathrm{W}}\right) \\
& -\frac{r^{\prime \prime}}{\bar{W}}\left(\mathrm{R}, \mathrm{W}-\mathrm{R}^{\prime} \mathrm{R}_{\mu}\right) \text {. }
\end{aligned}
$$

In case we adjust the bridge to $R_{l} W-R^{\prime} R_{l l}=0$ and a condenser is in $r^{\prime \prime}$ so that we can make $r^{\prime \prime}=0$, the value of $-b^{2} \mathrm{~L}_{c} c^{\prime \prime}$ will be indeterminate, and we can find $\frac{\mathrm{L}_{1}}{c^{\prime \prime}}$ by the adjustment of $\mathrm{W}$ alone.

This is an excellent method, apparently, as only one adjustment is required.

However, see the remarks on method 15. This present method with $r^{\prime \prime}=0$ for $\frac{\mathrm{L}}{c}$ is Anderson's, with, however, alternating currents instead of direct as in his.

The other two values are imaginary in this case. Indeed 
the whole method $(B)$ is only of special value for $\frac{L}{c}$, as two adjustments are needed for the others.

\section{Method 17.}

(A) $\mathrm{W}=\infty, \mathrm{R}=\infty$ :

$$
\begin{gathered}
b^{2} \mathrm{ML}^{\prime}=\mathbf{R}, \mathbf{R}^{\prime \prime}-\mathbf{R}_{/ /} \mathbf{R}^{\prime}, \\
\frac{\mathrm{L}^{\prime}}{\mathbf{M}}=\frac{\mathrm{R}^{\prime}+\mathbf{R}_{1}+\mathbf{R}^{\prime \prime}+\mathbf{R}_{\mu \prime} .}{\mathbf{R}_{/ \prime}} .
\end{gathered}
$$

By this method the self-induction of the mutual inductioncoil is eliminated. But it is difficult to apply, as two resistances must be adjusted, and the adjustment will only hold while the current period remains constant. The same remarks apply to (B) and (C) following.

(B) $R=\infty$ :

$$
\begin{gathered}
b^{2} \mathrm{ML}^{\prime}=\frac{\mathrm{W}\left[\mathbf{R}_{/} \mathbf{R}^{\prime \prime}-\mathrm{R}^{\prime} \mathbf{R}_{1 /}\right]}{\mathrm{W}^{\prime \prime \prime}+\mathbf{R}_{/}+\mathbf{R}_{/ \prime}}, \\
\frac{\mathrm{L}^{\prime}}{\mathrm{M}}=\frac{\mathrm{W}^{\prime \prime \prime}\left[\mathrm{R}^{\prime}+\mathrm{R}_{/}+\mathrm{R}^{\prime \prime}+\mathrm{R}_{/ /}\right]+\left(\mathrm{R}^{\prime}+\mathrm{R}_{/}\right)\left(\mathrm{R}^{\prime \prime}+\mathrm{R}_{/ \prime}\right)}{\mathrm{R}_{/ /} \mathrm{W}} .
\end{gathered}
$$

(C) $W=\infty:$

$$
\begin{gathered}
b^{2} \mathrm{ML}^{\prime}=\frac{\mathrm{R}}{\mathrm{R}+\mathrm{R}^{\prime \prime}+\mathrm{R}_{u}}\left(\mathrm{R}, \mathrm{R}^{\prime \prime}-\mathrm{R}^{\prime} \mathrm{R}_{/ \prime}\right), \\
\frac{\mathrm{L}^{\prime}}{\mathrm{M}}=\frac{\mathrm{R}\left(\mathrm{R}^{\prime}+\mathrm{R}_{,}+\mathrm{R}^{\prime \prime}+\mathrm{R}_{\| \prime}\right)+\left(\mathrm{R}^{\prime}+\mathrm{R}_{l}\right)\left(\mathrm{R}^{\prime \prime}+\mathrm{R}_{\| l}\right)}{\mathrm{RR}_{u}} .
\end{gathered}
$$

Method 18.

$$
\begin{gathered}
\mathrm{R}_{i} \mathrm{R}^{\prime \prime}-\mathrm{R}^{\prime} \mathrm{R}_{l \prime}=0, \\
\frac{\mathrm{L}^{\prime}}{\mathrm{M}^{\prime}}=1+\frac{\mathrm{R}^{\prime \prime}}{\mathrm{R}_{u}}+\frac{\mathrm{R}^{\prime}+\mathrm{R}^{\prime \prime}}{\mathrm{W}} .
\end{gathered}
$$

$\mathrm{L}^{\prime}$ and $\mathrm{M}^{\prime}$ belong to the same coil. By adjusting the Wheatstone bridge first, $W$ can then be afterwards adjusted.

To find the ratio for any other coil independent of the induction-coil, we can first find $\frac{L^{\prime}}{\bar{M}^{\prime}}$ as above. Then add $\mathrm{L}$ to the same circuit, and we can find $\frac{\mathrm{L}+\mathrm{I}^{\prime}}{\mathrm{M}^{\prime}}$. Whence wre can get L. This seems a convenient method if it is sensitive enough, as the value of $\frac{L^{\prime}}{\bar{M}^{\prime}}$ should be accurately known for the inductance standard. 
Method 19.

$$
\begin{gathered}
b^{2}\left(\mathrm{~L}^{\prime} l-\mathrm{M}^{2}\right)=\frac{r}{\mathrm{R}_{\mu}}\left[\mathrm{R}^{\prime} \mathrm{R}_{\prime \prime}-\mathrm{R}^{\prime \prime} \mathrm{R}_{i}\right], \\
\mathrm{L}^{\prime}=\frac{\mathrm{R}^{\prime}+\mathrm{R}_{l}}{r}-l^{2} \frac{\mathrm{L}^{\prime} l-\mathrm{M}^{2}}{r^{2}}\left(\frac{l}{\bar{M}}+1\right)=\frac{\mathrm{R}^{\prime}+\mathrm{R}_{f}}{r}-\frac{\mathrm{R}^{\prime} \mathrm{R}_{\prime \prime}-\mathrm{R}^{\prime \prime} \mathrm{R}_{l}}{r \mathrm{R}_{\prime \prime}}\left(\frac{l}{\bar{M}}+1\right) .
\end{gathered}
$$

This is useful in obtaining the constants of an induction standard. For twisted wires $L^{\prime} l-M^{2}$ should be nearly 0 , depending, as it does, on the magnetic leakage between the coils. $\frac{l}{\mathrm{M}}$ is often known sufficiently nearly for substitution in the right hand nember. It can, however, be found by reversing the inductance standard.

Method 20.

$$
\begin{aligned}
& \mathbf{R}^{\prime} \mathbf{R}_{/ /}-\mathbf{R}^{\prime \prime} \mathbf{R}_{d}=0 \text {, } \\
& \frac{\mathrm{M}}{\mathrm{L}}=\frac{\mathrm{R}^{\prime \prime}}{\mathrm{R}_{\imath}+\mathrm{R}_{/ \prime}} ; \frac{\mathrm{M}}{\mathrm{L}^{\prime}}=\frac{\mathrm{W}}{\mathrm{R}^{\prime \prime}} \frac{\mathrm{R}_{u}{ }^{2}}{\left(\mathrm{R}_{\imath}+\mathrm{R}_{u}\right)^{2}} ; \frac{\mathrm{L}}{\mathrm{L}^{\prime}}=\frac{\mathrm{W}}{\mathrm{R}^{\prime}+\mathrm{R}^{\prime \prime}} \mathrm{L}>\mathrm{M} ; \mathrm{L}^{\prime}
\end{aligned}
$$

In case of a standard inductance, $M$ and $L$ are known, especially when the wires are twisted.

The method can then be used for determining any other inductance, $\mathrm{L}^{\prime}$, and is very convenient for the purpose.

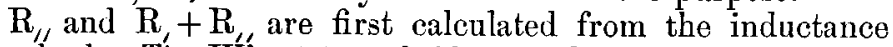
standard. The Wheatstone bridge is then adjusted and W varied until a balance is obtained. This balance is independent of the current period, as also in the next two methods.

$$
\begin{gathered}
\text { Method,21. } \\
\mathrm{R}^{\prime} \mathrm{R}_{l \prime}-\mathrm{R}^{\prime \prime} \mathrm{R}_{l}=0, \\
\frac{l}{\mathrm{M}}=\frac{\mathrm{R}^{\prime}+\mathrm{R}_{l}}{\mathrm{R} /} ; \frac{\mathrm{L}^{\prime}}{\mathrm{M}}=\frac{\left(\mathrm{R}^{\prime}+\mathrm{R}_{l}\right)^{2}}{r \mathrm{R}_{l}} ; \frac{\mathrm{L}^{\prime}}{l}=\frac{\mathrm{R}^{\prime}+\mathrm{R}_{l}}{r} l>\mathrm{M} .
\end{gathered}
$$

This is Niven's method adapted to alternating currents. See remarks to method 20.

Methods 20 and 21 are specially useful when one wishes to set up an apparatus for measuring self-induction, as the resistances $\mathbf{R}^{\prime}, \mathbf{R}^{\prime \prime}, \mathbf{R}_{/}, \mathbf{R}_{/,}$can be adjusted once for all in case of a given inductance standard and only $W$ or $r$ need be varied afterwards.

Plitl. Mag. S. 5. Vol. 45. No. 272. Jan. 1898. G G 


\section{Method 22.}

$$
\frac{\mathrm{L}^{\prime \prime}}{\mathrm{M}}=\frac{\mathrm{R}^{\prime}+\mathrm{R}}{\mathrm{R},} ; \frac{\mathrm{M}}{\mathrm{C}^{\prime}}=\mathrm{R}, \mathrm{R}^{\prime \prime} ; \frac{\mathrm{L}^{\prime \prime}}{\mathrm{C}^{\prime}}=\mathrm{R}^{\prime \prime}\left(\mathrm{R}^{\prime}+\mathrm{R}_{\iota}\right) .
$$

This is Carey Foster's method adapted to alternating currents and changed by making $R^{\prime \prime}$ finite instead of zero.

The ratio of $R^{\prime}+R$, to $R$, is computed from the known value of the induction standard. $R^{\prime \prime}$ is then adjusted and $C^{\prime}$ obtained. In general the adjustment can be obtained by changing $R$, and $R^{\prime \prime}$. The adjustment is independent of the current period.

$$
\begin{gathered}
\text { Method } 23 . \\
b^{2} m \mathrm{~L}^{\prime}=r \mathrm{R},+\mathrm{R}\left[r+\mathrm{R}^{\prime}+\mathrm{R}_{\ell}\right], \\
\frac{\mathrm{M}_{r}-\mathrm{L}^{\prime} \mathrm{R}}{m}=r+\mathrm{R}^{\prime}+\mathrm{R}_{,} .
\end{gathered}
$$

If we make $R=0$ we have

$$
\begin{gathered}
b^{2} m \mathrm{~L}^{\prime}=r \mathrm{R}, \\
\frac{\mathrm{M}}{m}=\frac{r+\mathrm{R}^{\prime}+\mathrm{R},}{r} .
\end{gathered}
$$

This method requires two simultaneous adjustments. M must also be greater than $m$. As $\mathrm{M}$ and $\mathrm{L}^{\prime}$ belong to the same coil, we can consider this mothod as one for determining $m$ in terms of the $M$ and $L^{\prime}$ of some standard coil.

The resistance, $A$, can be varied to test for, or even correct, the error due to electrostatic action between the wires of the induction standard.

$$
\begin{gathered}
\text { Method } 24 . \\
\frac{\mathrm{L}_{1}}{\mathrm{M}_{1}}=\frac{\mathrm{L}^{\prime}}{\overline{\mathrm{M}}^{\prime}} \frac{r_{\prime}^{\prime}}{r^{\prime}} ; \frac{\mathrm{M}_{\prime}^{\prime}}{\overline{\mathrm{M}}^{\prime}}=\frac{r^{\prime}\left(r_{1}+\mathrm{R}_{1}+\mathrm{R}_{\prime \prime}\right)}{r_{/}\left(r^{\prime}+\mathrm{R}^{\prime}+\overline{\mathrm{R}}^{\prime \prime}\right)} .
\end{gathered}
$$

This is a good method for comparing standards. We first determine $\frac{\mathrm{L}_{h l}}{\mathrm{M}}$ for each coil by one of the previous methods. Then we can calculate $\frac{r_{l}}{r^{\prime}}$ and adjust the other resistances to balance.

It is independent of the period of the current and suitable for standards of equal as well as of different values, as the mutual inductances can have any ratio to each other.

For twisted wire coils $r,=r^{\prime}$ very nearly. See method 23 for the use of the resistance, $A$. 


\section{Method 25.}

In fig. 6 remove the shunt $\mathbf{R}^{\prime}$ and self-induction $\mathrm{L}$.

This method then depends upon the measurement of the angular deflexion when a self-induction or a capacity is put in the circuit of the small coil of the electrodynamometer, and comparing this with the deflexion when the circuit only contains resistance.

The resistance of the circuit, $r$, is supposed to be so great compared with $\mathrm{R}$ that the current in the main circuit remains practically unaltered during the change.

There is also an error due to the mutual induction of the electrodynamometer-coils which vanishes when $r$ is great.

$$
\frac{1}{b^{2} c^{2}} \text { or } b^{2} l^{2}=\mathrm{R}^{\prime \prime}\left[r+\mathrm{R}^{\prime \prime}\right]\left[\frac{r_{1}+\mathrm{R}_{/}^{\prime \prime}}{\mathbf{R}_{/}^{\prime \prime}} \frac{\theta_{1}}{\theta}-\frac{r+\mathbf{R}^{\prime \prime}}{\mathbf{R}^{\prime \prime}}\right] \text {. }
$$

These formulas assume that the deflexion is proportional to $\theta$. This assumption cun be obviated by adjusting $\theta=\theta^{\prime}$, when we have

$$
\frac{1}{b^{2} v^{2}} \text { or } b^{2} l^{2}=\frac{\left(r+\mathrm{R}^{\prime \prime}\right)\left(r, \mathrm{R}^{\prime \prime}-r \mathrm{R}_{\prime}^{\prime \prime}\right)}{\mathrm{R}} .
$$

These can be further simplified by making $R^{\prime \prime}=R_{,}^{\prime \prime}$.

The method thus becomes very easy to apply and capable of considerable accuracy. As the absolute determination depends on the current period, however, no great accuracy can be expected for absolute values except where this period is known and constant, a condition almost impossible to be obtained. The comparison of condensers or of inductances is, however, independent of the period and can be carried out, however variable the period, by means of a key to make the change instantaneously.

\section{Method 26.}

Similar results can be obtained by putting the condenser or inductance in $\mathbf{R}^{\prime \prime}$ instead of $r$, but the current through the electrodynamometer suspension is usually too great in this case unless $r$ is enormous. We have in this case for equal deflexions,

$$
\frac{1}{b^{2} \mathrm{C}^{\prime / 2}} \text { or } b^{2} \mathrm{~L}^{\prime \prime 2}=\mathrm{R}^{\prime \prime}\left(\mathrm{R}^{\prime \prime}+r\right)\left(\frac{r \mathrm{R}_{\prime}^{\prime \prime}-r_{,} \mathrm{R}^{\prime \prime}}{r, \mathrm{R}^{\prime \prime}}\right),
$$

where $r$, and $\mathrm{R}_{l}^{\prime \prime}$ are the resistances without condenser or self-induction.

This is a very good method in many respects. 
For using 25 and 26, a key to make instantaneous change of connexions is almost necessary.

\section{Method 27.}

To measure resistance by alternating currents, a Wheatstone bridge is often used with a telephone.

I propose to increase the sensitiveness of the method by using my method of passing a strong current through the fixed coils of an electrodynamometer while the weaker testing: current goes through the suspended system.

Using non-inductive resistances, methods $10,13 \mathrm{~A}, \mathrm{~B}, \mathrm{C}$, and 14 all reduce to proper ones. 10 or 14 is specially good and I have no doubt will be of great value for liquid resistances. The liquid resistances must, however, be properly designed to avoid polarization errors. The increase of accuracy over using the electrodynamometer in the usual manner is of the order of magnitude of 1000 times.

By this method, a resistance of $10,000,000 \mathrm{ohms}$ can be measured to 1 part in 1000 or even more. This method should play a great part in future work on liquid resistances.

Since writing the above I have tried some of the methods, especially 6 and 12 . By the method 12, results to 1 in 1000 can be obtained. Replacing $L^{\prime}$ by an equal coil, the ratio of the two, all other errors being eliminated, can be obtained to 1 in 10,000 , or even more accurately.

The main error to be guarded against in method 12 , or any other where large inductances or resistances are included, arises from twisting the wires leading to these. The electrostatic action of the leads or the twisted wire coils of an ordinary resistance-box, may cause errors of several per cent. Using short small wire leads far apart, the error becomes very small.

Method 6 is also very accurate, but the electric absorption of the condensers makes much accuracy impossible unless a series of experiments is made to determine the apparent resistance due to this cause.

In method $12 \mathrm{I}$ have not yet detected any error due to twisting the wires of coils $l$. However, the electrostatic action of twisted wire coils is immense, and the warning against their use which I have given above has been well substantiated by experiment. Only in case of low resistances and low inductances, or in cases like that just mentioned, is it to be tolerated for a moment. Connecting two twisted wires in a coil in series with a resistance between $I$ have 
almost neutralized the self-inductance, which was one henry for each coil, or four henrys for them in series.

Altogether the results of experiment justify me in claiming that these methods will take a prominent place in electrical measurement, especially where fluid resistances, inductances, and capacities are to be measured. They also seem to me to settle the question as to standard inductances or capacities, as inductances have a real constant which can now be compared to 1 in 10,000 at least.

It is to be noted that all the methods 15 to 24 can bo modified by passing the main current through one coil of the electrodynamometer and the branch current through the other. The deflexion will then be zero for a more complicated relation than the ones given. If, however, one adjustment is known and made, the method gives the other equation.

Thus method 18 requires $R_{l} R^{\prime \prime}-R^{\prime} R_{\mu}=0$. Hence, when this is satisfied we must have the other condition alone to be satisfied. Also in method 22, when wo know the ratio of the self and mutual inductances in the coil, the resistances can be adjusted to satisfy one equation, while the experiment will give the other, and hence the capacity in terms of the inductance. Again, pass a current whose phase can be varied through one coil of the electrodynamometer, and connect the circuit to be tested through the other. Vary the adjustments of resistances until the deflexion is zero, however the phase of current through the first coil may be varied.

The best methods to apply the first moditication to are $15 \mathrm{~A}, 16 \mathrm{~A}$ and $\mathrm{B}, 18,20,21,22$, and 24 . In these either a Wheatstone bridge can be adjusted or the ratio of the self and mutual inductances in a given coil can be assumed known and the resistance adjusted thereby.

The value of this addition is in the increased accuracy and sensitiveness of the method, an increase of more than one hundredfold being assured.

As a standard I recommend two or three coils laid together with their inductances determined, and not a condenser, even an air condenser.

VI. A New Harmonic Analyser.

By A. A. Michelson and S. W. Stratton*.

[Plates XI.-XVIII.]

GVERYONE who has had occasion to calculate or to conE struct graphically the resultant of a large number of simple harmonic motions, has felt the need of some simple

* Communicated by the Authors. 